\title{
From the Editor's Keyboard...
}

Congratulations once again on MESA's first 40 years!! For forty years, and counting, MESA has played a vital role in the building of a community of scholars, students, teachers, and public intellectuals united by their curiosity about the peoples, languages, cultures and histories of the Middle East. With this second issue of Volume 40 of the Bulletin, we continue our celebration of the accomplishments of the first decades, take stock of our progress, and look to the future of the organization and of the field of Middle East studies.

The centerpiece of issue 40/2 is "A People's History of MESA." Over the course of 2006 Nancy Dishaw conducted telephone interviews with more than sixty founding and early members of MESA. She asked each a series of questions, concerning their memories of the founding and early meetings of MESA, and asked them to comment on the present and future of MESA. Assistant Editor Adam Carey and I compiled excerpts from these interviews, arranging them in alphabetical, or reverse alphabetical, order. I think "A People's History" makes for fascinating reading, and I hope you agree.

The cover photo comes from our second winning entry in the $40^{\text {th }}$ Anniversary Cover Photo/Essay Contest, presented by Melanie Ames Arnold. Also in this issue you'll find two sketches of the MESA FilmFest, by Ron Bartholomew and Elizabeth Fernea.

Just as MESA is your organization, the Bulletin is your journal. Please let me know what you think of this issue, and please send me your suggestions for the next issue.

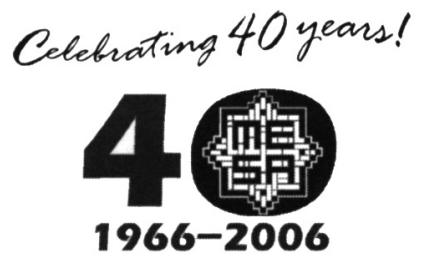

